\title{
PENGARUH KUALITAS PRODUK, HARGA DAN WORD OF MOUTH TERHADAP KEPUTUSAN PEMBELIAN KARATE-GI MEREK HOKIDO DI LIMA DOJO WILAYAH DKI JAKARTA
}

\author{
Hajir Masturi \\ Resti Hardini \\ Email: hajirmasturi2@gmail.com, resti.hardini@yahoo.com \\ Program Studi Manajemen Fakultas Ekonomi \\ Universitas Nasional
}

\begin{abstract}
ABSTRAK
Penelitian ini bertujuan untuk menguji dan menganalisis pengaruh kualitas produk, harga, dan word of mouth terhadap keputusan pembelian karate-gi merek Hokido di lima Dojo di wilayah DKI Jakarta. Populasi yang digunakan dalam penelitian ini adalah konsumen yang membeli karate-gi merek Hokido di lima Dojo di wilayah DKI Jakarta. Dengan menggunakan rumus William, jumlah sampel yang digunakan dalam penelitian ini adalah 100 responden. Metode analisis yang digunakan adalah regresi linear berganda. Hasil penelitian menunjukkan bahwa kualitas produk, harga dan word of mouth secara parsial berpengaruh positif dan signifikan terhadap keputusan pembelian karate-gi merek Hokido di lima Dojo di wilayah DKI Jakarta.
\end{abstract}

Kata kunci: Kualitas produk, harga, word of mouth, keputusan pembelian

\section{ABSTRACT}

This study aims to test and analyze the effect of product quality, price and word of mouth on purchasing decisions of karate-gi of Hokido brand in five Dojos region in DKI Jakarta. Population used in this study was consumers that bought karate-gi of Hokido brand in five Dojos in DKI Jakarta region. By used William formula, the amount of samples used in this study was 100 respondents. Method of analysis that used in this study was multiple linear regression. Results of the study showed that product quality, price and word of mouth partially has positive and significant effect on purchasing decision of karate-gi of Hokido Brand in five Dojos in DKI Jakarta region.

Keyword: Product quality, price, word of mouth, and purchasing decision

\section{PENDAHULUAN}

Semakin ketatnya persaingan dalam dunia bisnis membuat para pengusaha harus mencari strategi yang tepat untuk memasarkan produknya. Perusahaan harus mampu memahami dan memenuhi kebutuhan dan keinginan konsumennya. Perlunya pemahaman atas kebutuhan dan keinginan konsumen ini didasarkan pada pemikiran bahwa konsumen merupakan pasar sasaran produk. Jika suatu produk dianggap mampu memuaskan keinginan dan kebutuhan konsumen, maka konsumen tersebut akan membelinya. Sebaliknya, jika produk tersebut dianggap belum mampu memenuhi kebutuhan dan keinginan konsumen, maka konsumen tidak akan membeli produk tersebut. 
Pentingnya olahraga bagi kesehatan menjadikan olahraga sebuah kebutuhan yang penting bagi masyarakat modern. Salah satu olahraga modern yang banyak diminati oleh masyarakat adalah olahraga beladiri Karate. Karate merupakan olahraga yang berasal dari Jepang. Karate identik dengan karate-gi, yaitu seragamnya yang berwarna putih dengan model yang menyerupai kimono. Maraknya perkembangan karate di Indonesia memicu bertambahnya permintaan terhadap karate-gi.

Adanya peluang bisnis yang menjanjikan dari industri karate-gi memicu bermunculannya produsen karate-gi, baik dari dalam negeri maupun luar negeri. Hokido merupakan salah satu produsen karate-gi dalam negeri yang menghadapi ketatnya persaingan di industri karate-gi.

Penjualan karate-gi Hokido mengalami penurunan selama tiga tahun terakhir, yaitu dari 11.499 baju di tahun 2013 menjadi 10.651 baju di tahun 2015. Hal tersebut menunjukkan adanya penurunan tingkat keputusan pembelian masyarakat terhadap karate-gi merek Hokido. Perusahaan perlu mengambil tindakan yang tepat untuk mencegah terjadinya penurunan penjualan di tahun-tahun berikutnya. Oleh karena itu, perlu dilakukan penelitian untuk menguji dan menganalisis faktor-faktor yang mempengaruhi keputusan pembelian karate-gi merek Hokido.

Kualitas produk berpengaruh positif terhadap keputusan pembelian. Hal tersebut sesuai dengan hasil penelitian yang dilakukan oleh Mokoagouw (2016) dan Lotulung, et al. (2015). Produk yang berkualitas tinggi akan memiliki keunggulan bersaing (competitive advantage), sehingga keputusan pembelian terhadap produk tersebut juga tinggi.

Penelitian yang dilakukan oleh Mokoagouw (2016) dan Ratnaningrum (2016) menunjukkan bahwa harga berpengaruh positif terhadap keputusan pembelian. Faktor-faktor terkait harga yang dapat mempengaruhi keputusan pembelian antara lain keterjangkauan harga, perbandingan antara harga dan manfaat yang diterima, serta kemampuan bersaing dengan harga merek lain (Ratnaningrum, 2016). Produk yang memiliki harga yang terjangkau dapat menarik minat beli lebih banyak konsumen dengan latar belakang ekonomi yang lebih beragam. Produk yang memiliki harga yang sesuai dengan manfaat yang diterima dan mampu bersaing dengan harga merek lain juga dapat menarik lebih banyak konsumen untuk membelinya.

Hasil penelitian yang dilakukan oleh Hidayati, dkk. (2015) menunjukkan bahwa word of mouth berpengaruh positif terhadap keputusan pembelian. Menurut Word of Mouth Marketing Association (WOMA), word of mouth adalah suatu aktivitas dimana konsumen memberikan informasi mengenai suatu merek atau produk kepada konsumen lain. Perusahaan 
dapat mendorong dan memfasilitasi percakapan dari mulut ke mulut tersebut dengan memastikan terlebih dahulu bahwa produk atau merek dari perusahaan bersifat unik, inovatif dan patut menjadi conversation product (Yosevina, 2008:13). Word of mouth yang positif akan membantu perusahaan dalam mempromosikan produknya ke masyarakat luas dan pada akhirnya meningkatkan keputusan pembelian terhadap produk tersebut.

Berdasarkan latar belakang di atas, perlu dilakukan penelitian untuk menguji dan menganalisis pengaruh kualitas produk, harga dan word of mouth terhadap keputusan pembelian karate-gi merek Hokido.

\section{TINJAUAN PUSTAKA}

\section{Keputusan Pembelian}

Keputusan pembelian merupakan suatu keputusan sebagai pemilihan suatu tindakan dari dua atau lebih pilihan alternatif (Schiffman dan Kanuk, 2008). Menurut Kotler dan Armstrong (2008:181), keputusan pembelian konsumen adalah membeli merek yang paling disukai dari berbagai alternatif yang ada, tetapi dua faktor bisa berada antara niat pembelian dan keputusan pembelian.

\section{Kualitas Produk}

Menurut Kotler dan keller (2013:9), kualitas produk adalah kemampuan suatu produk dalam memberikan kinerja sesuai dengan fungsinya. Kualitas produk merupakan semua dimensi penawaran produk yang menghasilkan manfaat bagi pelanggan (Tjiptono 2008:67).

\section{Harga}

Menurut Kotler dan Armstrong (2008), harga adalah jumlah uang yang ditagihkan atas suatu produk atau jasa. Lebih luas lagi, harga adalah jumlah semua nilai yang diberikan oleh pelanggan untuk mendapatkan keuntungan dari memiliki atau menggunakan suatu produk atau jasa.

\section{Word of Mouth}

Menurut Lupiyoadi (2006:238), word of mouth adalah suatu bentuk promosi yang berupa rekomendasi dari mulut ke mulut tentang kebaikan dalam suatu produk. Menurut Word of Mouth Marketing Assoctation (WOMA), word of mouth adalah suatu aktivitas dimana konsumen memberikan informasi mengenai suatu merek atau produk kepada konsumen lain. Perusahaan dapat mendorong dan memfasilitasi percakapan dari mulut ke 
mulut tersebut dengan memastikan terlebih dahulu bahwa produk atau merek dari perusahaan bersifat unik, inovatif dan patut menjadi conversation product (Yosevina, 2008:13).

\section{Keterkaitan Antarvariabel Penelitian}

\section{Keterkaitan antara Kualitas Produk dan Keputusan Pembelian}

Menurut Tjiptono (2008:98) kualitas produk mempunyai hubungan yang sangat erat dengan sikap konsumen dimana kualitas produk memberikan suatu dorongan kepada konsumen untuk menjalin ikatan hubungan yang kuat dengan perusahaan. Hasil penelitian yang dilakukan oleh Mokoagouw (2016) dan Lotulung, et al. (2015) menunjukkan bahwa kualitas produk berpengaruh positif terhadap keputusan pembelian. Produk yang berkualitas tinggi akan memiliki keunggulan bersaing (competitive advantage), sehingga keputusan pembelian terhadap produk tersebut juga tinggi.

$\mathrm{H}_{1}$ : Kualitas produk berpengaruh positif dan signifikan terhadap keputusan pembelian karategi merek Hokido di lima Dojo di wilayah DKI Jakarta.

\section{Keterkaitan antara Harga dan Keputusan Pembelian}

Penelitian yang dilakukan oleh Mokoagouw (2016) dan Ratnaningrum (2016) menunjukkan bahwa harga berpengaruh positif terhadap keputusan pembelian. Faktor-faktor terkait harga yang dapat mempengaruhi keputusan pembelian antara lain keterjangkauan harga, kesesuaian antara harga dan manfaat yang diterima, serta kemampuan bersaing dengan harga merek lain (Ratnaningrum, 2016).

$\mathrm{H}_{2}$ : Harga berpengaruh positif dan signifikan terhadap keputusan pembelian karate-gi merek Hokido di lima Dojo di wilayah DKI Jakarta.

\section{Keterkaitan antara Word of Mouth dan Keputusan Pembelian}

Hasil penelitian yang dilakukan oleh Hidayati, dkk. (2015) menunjukkan bahwa word of mouth berpengaruh positif terhadap keputusan pembelian. Menurut Word of Mouth Marketing Assoctation (WOMA), word of mouth adalah suatu aktivitas dimana konsumen memberikan informasi mengenai suatu merek atau produk kepada konsumen lain. Perusahaan dapat mendorong dan memfasilitasi percakapan dari mulut ke mulut tersebut dengan memastikan terlebih dahulu bahwa produk atau merek dari perusahaan bersifat unik, inovatif 
dan patut menjadi conversation product (Yosevina, 2008:13). Word of mouth yang positif akan meningkatkan keputusan pembelian terhadap produk dan penjualan perusahaan

$\mathrm{H}_{3}$ : Word of mouth berpengaruh positif dan signifikan terhadap keputusan pembelian karategi merek Hokido di lima Dojo di wilayah DKI Jakarta.

\section{Kerangka Analisis}

Penelitian ini menggunakan kerangka analisis sebagai berikut.

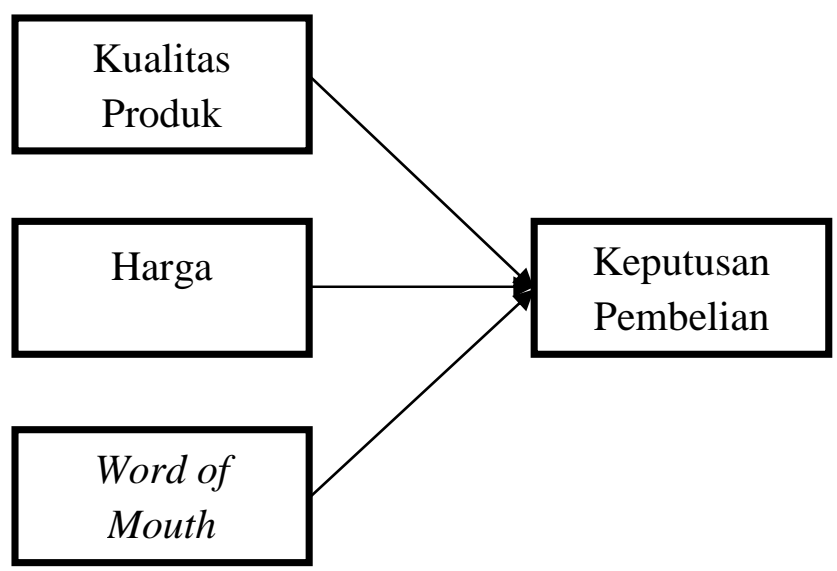

Gambar 1. Kerangka Analisis

\section{METODE PENELITIAN}

\section{Sumber dan Jenis Data}

Penelitian ini menggunakan data primer yang bersumber dari jawaban kuesioner yang dibagikan kepada responden.

\section{Populasi dan Sampel}

Populasi dalam penelitian ini adalah konsumen yang membeli karate-gi merek Hokido di lima Dojo di wilayah DKI Jakarta. dimana jumlah populasinya tidak diketahui. Jumlah sampel penelitian ditentukan menggunakan rumus William, yaitu sebagai berikut.

$$
\mathrm{n}=\frac{(\mathrm{Z} \alpha / 2)^{2} \mathrm{P}^{*}\left(1-\mathrm{P}^{*}\right)}{\mathrm{E}^{2}}
$$

Keterangan:

$\mathrm{P}^{*} \quad=$ Proporsi populasi $=0,5$

$\mathrm{E}=$ Batas toleransi kesalahan $10 \%=0,10$

$\alpha \quad=0,05$

$\mathrm{Z} \alpha / 2=$ Skor distribusi normal dengan taraf nyata $5 \%=1,96$ 
Berdasarkan rumus tersebut, jumlah sampel dalam penelitian ini adalah 96 responden atau dibulatkan menjadi 100 responden.

\section{Definisi Operasional Variabel}

Berikut ini merupakan definisi operasional variabel dalam penelitian ini.

Tabel 1. Definisi Operasional Variabel

\begin{tabular}{|c|c|c|}
\hline Variabel & Definisi Operasional & Indikator \\
\hline Kualitas Produk & $\begin{array}{l}\text { Kemampuan produk baju karate-gi } \\
\text { hokido dalam memberikan kinerja } \\
\text { sesuai dengan fungsinya. }\end{array}$ & $\begin{array}{ll}\text { 1. } & \text { Kinerja } \\
\text { 2. } & \text { Ketahanan } \\
\text { 3. } & \text { Keandalan } \\
\text { 4. } & \text { Desain }\end{array}$ \\
\hline Harga & $\begin{array}{l}\text { Jumlah uang yang ditagihkan atas } \\
\text { produk baju karate-gi Hokido untuk } \\
\text { mendapatkan keuntungan dari } \\
\text { memiliki atau menggunakan produk } \\
\text { karate-gi merek hokido. }\end{array}$ & $\begin{array}{l}\text { 1. Keterjangkauan harga } \\
\text { 2. Kesesuaian harga dengan } \\
\text { kualitas } \\
\text { 3. Daya saing harga } \\
\text { 4. Kesesuaian harga dengan } \\
\text { manfaat }\end{array}$ \\
\hline Word of Mouth & $\begin{array}{l}\text { Suatu bentuk promosi yang berupa } \\
\text { rekomendasi dari mulut ke mulut } \\
\text { tentang keunggulan produk karate-gi } \\
\text { merek hokido. }\end{array}$ & $\begin{array}{l}\text { 1. Bicara hal positif } \\
\text { 2. Rekomendasi } \\
\text { 3. Dorongan }\end{array}$ \\
\hline Keputusan Pembelian & $\begin{array}{l}\text { Suatu keputusan konsumen untuk } \\
\text { membeli karate-gi merek Hokido. }\end{array}$ & $\begin{array}{l}\text { 1. Cepat dalam memutuskan } \\
\text { 2. Bertindak karena } \\
\text { keunggulan produk } \\
\text { 3. Keyakinan atas pembelian }\end{array}$ \\
\hline
\end{tabular}

\section{Metode Analisis}

Metode analisis dalam penelitian ini adalah regresi linear berganda yang ditujukan untuk menganalisis pengaruh variabel-variabel independen terhadap variabel terikat.

\section{HASIL PENELITIAN}

\section{Hasil Uji Validitas dan Reliabilitas}

Hasil uji validitas menyatakan bahwa semua butir pernyataan untuk variabel kualitas produk, harga, word of mouth dan keputusan pembelian bersifat valid karena memiliki $\mathbf{r}_{\text {hitung }}$ yang lebih besar daripada $r_{\text {tabel }}(0,165)$. 
Hasil uji reliabilitas menunjukkan bahwa semua variabel dalam penelitian ini mempunyai nilai cronbach's alpha di atas 0,60, sehingga semua konsep pengukur masingmasing variabel dari kuesioner dinyatakan reliabel.

\section{Hasil Uji Asumsi Klasik}

\section{Hasil Uji Normalitas}

Tabel 2. Hasil Uji Normalitas

\begin{tabular}{|c|c|c|}
\hline Asymp. Sig. (2-Tailed) & $\boldsymbol{\alpha}$ & Keterangan \\
\hline 0,624 & 0,05 & Normal \\
\hline
\end{tabular}

Sumber: Data diolah (2016)

Berdasarkan hasil uji normalitas, diperoleh asymp. sig. sebesar 0,624 > 0,05, sehingga data terdistribusi normal.

\section{Hasil Uji Autokorelasi}

Berdasarkan hasil uji autokorelasi, diketahui besarnya nilai Durbin-Watson adalah 1,866. Pada tingkat signifikan 5\% dengan jumlah sampel sebanyak $100(\mathrm{n}=100)$ dan jumlah variabel bebas sebanyak $3(\mathrm{k}=3)$, diperoleh nilai $\mathrm{dL}=1,613$ dan $\mathrm{dU}=1,736$. Hal tersebut menunjukkan bahwa model yang digunakan dalam penelitian ini memenuhi kriteria dU < DW $<4-$ dU $(1,736<1,866<2,264)$, sehingga tidak ada autokorelasi dalam model regresi ini.

\section{Hasil Uji Heteroskedastisitas}

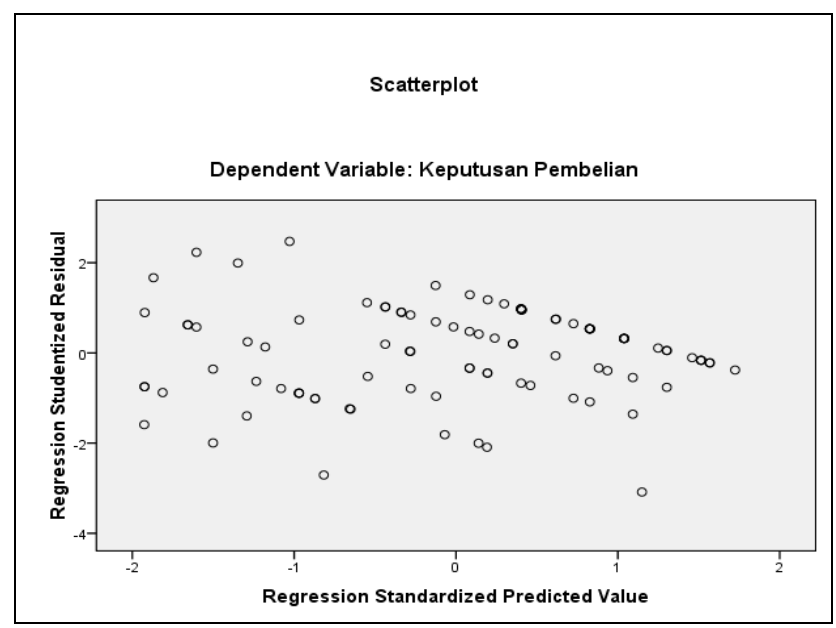

Sumber: Data diolah (2016)

Gambar 2. Scatterplot Hasil Uji Heteroskedastisitas 
Berdasarkan scatterplot di atas, dapat dilihat bahwa titik-titik menyebar dengan pola yang tidak jelas di atas dan di bawah angka 0 pada sumbu Y, sehingga tidak terjadi masalah heteroskedastisitas dalam model regresi ini.

\section{Uji Multikolinearitas}

Tabel 3. Hasil Uji Multikolinearitas

\begin{tabular}{|l|r|c|}
\hline \multirow{2}{*}{ Variabel } & \multicolumn{2}{|c|}{ Collinearity Statistics } \\
\cline { 2 - 3 } & Tolerance & VIF \\
\hline Kualitas Produk & 0.589 & 1.697 \\
Harga & 0.596 & 1.677 \\
Word of Mouth & 0.839 & 1.191 \\
\hline
\end{tabular}

Berdasarkan tabel di atas, setiap variabel mempunyai nilai tolerance $>0,1$ dan VIF $<$ 10, sehingga tidak terdapat multikolinearitas dalam model regresi ini.

\section{Regresi Linear Berganda}

Tabel 4. Hasil Uji Regresi Linear Berganda

\begin{tabular}{|l|c|r|r|r|l|}
\hline \multirow{2}{*}{ Variabel } & \multicolumn{2}{|c|}{$\begin{array}{c}\text { Unstandardized } \\
\text { Coefficients }\end{array}$} & $\begin{array}{c}\text { Standardized } \\
\text { Coefficients }\end{array}$ & \multirow{2}{*}{ T } & \multirow{2}{*}{ Sig. } \\
\cline { 2 - 5 } & \multicolumn{1}{|c|}{ B } & Std. Error & \multicolumn{1}{|c|}{ Beta } & & \\
\hline (Constant) & 3.640 & 1.483 & & 2.454 & 0.016 \\
Kualitas Produk & 0.331 & 0.093 & 0.332 & 3.555 & 0.001 \\
Harga & 0.264 & 0.087 & 0.280 & 3.022 & 0.003 \\
Word of Mouth & 0.262 & 0.073 & 0.282 & 3.607 & 0.000 \\
\hline
\end{tabular}

Berdasarkan standardized coefficients pada tabel di atas, diperoleh persamaan regresi linear berganda sebagai berikut.

$$
Y=0,332 X_{1}+0,280 X_{2}+0,282 X_{3}
$$

Keterangan:

$$
\begin{array}{ll}
\mathrm{Y} & : \text { Keputusan Pembelian } \\
\mathrm{X}_{1} & : \text { Kualitas Produk } \\
\mathrm{X}_{2} & : \text { Harga } \\
\mathrm{X}_{3} & : \text { Word of Mouth }
\end{array}
$$




\section{Hasil Uji Kelayakan Model}

\section{Uji F}

Tabel 5. Hasil Uji F

\begin{tabular}{|l|r|r|r|c|c|}
\hline \multicolumn{1}{|c|}{ Model } & $\begin{array}{l}\text { Sum of } \\
\text { Squares }\end{array}$ & Df & $\begin{array}{c}\text { Mean } \\
\text { Square }\end{array}$ & F & Sig. \\
\hline Regression & 154.071 & 3 & 51.357 & 33.019 & 0.000 \\
Residual & 149.319 & 96 & 1.555 & & \\
Total & 303.390 & 99 & & & \\
\hline
\end{tabular}

Sumber: Data diolah (2016)

Berdasarkan tabel di atas, diketahui adanya nilai sig. sebesar 0,000 yang lebih kecil daripada 0,05 , sehingga dapat disimpulkan bahwa kualitas produk, harga dan word of mouth secara bersama-sama berpengaruh signifikan terhadap keputusan pembelian. Hal tersebut menunjukkan bahwa model dan variabel yang digunakan dalam penelitian ini layak dan mampu menjelaskan model yang dianalisis.

\section{Koefisien Determinasi $\left(\mathbf{R}^{2}\right)$}

Berdasarkan hasil penelitian, diperoleh koefisien korelasi $(\mathrm{R})$ sebesar 0,713 dan $\mathrm{R}^{2}$ sebesar 0,508. Nilai koefisien determinasi $\left(\mathrm{R}^{2}\right)$ sebesar 50,8\% menunjukkan bahwa kualitas produk, harga dan word of mouth memberikan kontribusi sebesar 50,8\% dalam menjelaskan keputusan pembelian, sedangkan 49,2\% sisanya dijelaskan oleh variabel-variabel lain yang tidak dianalisis dalam penelitian ini.

\section{Pengujian Hipotesis (Uji T)}

Berdasarkan tabel 5, diperoleh nilai $\mathrm{t}_{\text {hitung }}$ kualitas produk sebesar 3.555 yang berada pada tingkat signifikansi 0,001 yang lebih kecil daripada 0,05, sehingga $\mathrm{H}_{0}$ ditolak dan $\mathrm{Ha}$ diterima. Hal tersebut menunjukkan bahwa kualitas produk berpengaruh positif dan signifikan terhadap keputusan pembelian karate-gi merek Hokido di lima Dojo di wilayah DKI Jakarta.

Nilai $\mathrm{t}_{\text {hitung }}$ harga sebesar 3.022 berada pada tingkat signifikansi 0,003 yang lebih kecil daripada 0,05 , sehingga $\mathrm{H}_{0}$ ditolak dan Ha diterima. Hal tersebut menunjukkan bahwa harga berpengaruh positif dan signifikan terhadap keputusan pembelian karate-gi merek Hokido di lima Dojo di wilayah DKI Jakarta.

Nilai $\mathrm{t}_{\text {hitung }}$ word of mouth sebesar 3,607 berada pada tingkat signifikansi 0,000 yang lebih kecil daripada 0,05 , sehingga $\mathrm{H}_{0}$ ditolak dan $\mathrm{Ha}$ diterima. Hal tersebut menunjukkan 
bahwa word of mouth berpengaruh positif dan signifikan terhadap keputusan pembelian karate-gi merek Hokido di lima Dojo di wilayah DKI Jakarta.

\section{Pembahasan}

\section{Pengaruh Kualitas Produk terhadap Keputusan Pembelian}

Berdasarkan hasil penelitian, dapat diketahui bahwa kualitas produk berpengaruh positif dan signifikan terhadap keputusan pembelian karate-gi merek Hokido di lima Dojo di wilayah DKI Jakarta. Artinya, semakin tinggi kualitas suatu produk, maka semakin tinggi pula tingkat keputusan pembelian terhadap produk tersebut. Produk yang berkualitas tinggi akan menciptakan kepuasan konsumen sehingga meningkatkan keputusan pembelian konsumen terhadap produk tersebut. Hasil penelitian ini sesuai dengan hasil penelitian yang dilakukan oleh Lotulung, et al. (2015) dan Karlina dan Seminari (2015) yang menyatakan bahwa kualitas produk berpengaruh positif dan signifikan terhadap keputusan pembelian.

\section{Pengaruh Harga terhadap Keputusan Pembelian}

Berdasarkan hasil penelitian, dapat diketahui bahwa harga berpengaruh positif dan signifikan terhadap keputusan pembelian karate-gi merek Hokido di lima Dojo di wilayah DKI Jakarta. Artinya, semakin tinggi keterjangkauan suatu produk, maka semakin tinggi pula tingkat keputusan pembelian terhadap produk tersebut. Hasil penelitian ini juga didukung oleh penelitian yang dilakukan oleh Mokoagouw (2016:501) yang menyatakan bahwa harga berpengaruh positif dan signifikan terhadap keputusan pembelian. Berdasarkan hasil penelitian tersebut, perusahaan perlu memonitor harga yang ditetapkan oleh para pesaing agar harga yang ditawarkan oleh perusahaan itu sendiri dapat menimbulkan keinginan konsumen untuk melakukan pembelian.

\section{Pengaruh Word of Mouth terhadap Keputusan Pembelian}

Berdasarkan hasil penelitian, dapat diketahui bahwa word of mouth berpengaruh positif dan signifikan terhadap keputusan pembelian karate-gi merek Hokido di lima Dojo di wilayah DKI Jakarta. Artinya, semakin tinggi tingkat word of mouth yang positif atas suatu produk, maka semakin tinggi pula tingkat keputusan pembelian terhadap produk tersebut. Hal tersebut dikarenakan cerita mengenai pengalaman baik seseorang dalam menggunakan suatu produk dapat mempengaruhi orang-orang yang mendengarkan pengalaman tersebut untuk membuat keputusan pembelian atas produk tersebut. Hasil penelitian ini sesuai dengan hasil 
penelitian yang dilakukan oleh Hidayati, dkk. (2015) yang menyatakan bahwa word of mouth berpengaruh positif terhadap keputusan pembelian.

\section{KESIMPULAN DAN SARAN}

\section{Kesimpulan}

Berdasarkan hasil penelitian, dapat diperoleh kesimpulan bahwa kualitas produk, harga dan word of mouth secara parsial berpengaruh positif dan signifikan terhadap keputusan pembelian produk karate-gi merek Hokido di lima Dojo di wilayah DKI Jakarta.

\section{Saran}

Berdasarkan kesimpulan di atas, perusahaan Hokido perlu mempertahankan dan meningkatkan kualitas karate-gi yang diproduksinya agar dapat meningkatkan positive word of mouth dan keputusan pembelian terhadap produk tersebut. Perusahaan juga perlu mempertimbangkan keterjangkauan harga, kesesuaiannya dengan manfaat yang ditawarkan dan harga pesaing saat menentukan harga karate-gi yang akan dijualnya. Hal tersebut perlu dilakukan untuk meningkatkan keputusan pembelian terhadap karate-gi yang diproduksinya.

\section{DAFTAR PUSTAKA}

Hidayati, N., S.R.T Astuti., dan Nurhidayati. 2015. Analisis Pengaruh Kualitas Pelayanan, Persepsi Harga, Kualitas Produk dan Word of Mouth terhadap Keputusan Pembelian Konsumen: Studi pada Toko Seni Kerajinan Mas dan Perak Sulaiman Intan Permata di Semarang. Diponegoro Journal Of Management. 4 (1): 2337-3792.

Karlina, N.P.N. dan N.K. Seminari. 2015. Pengaruh Citra Merek dan Kualitas Produk terhadap Keputusan Pembelian Produk PT Karya Pak Oles Tokcer Denpasar. EJurnal Manajemen Unud. 4(6): 1610-1623.

Kotler, P. dan G. Armstrong. 2008. Principles of Marketing. $12^{\text {th }}$ ed. Pearson Prentice Hall. New Jersey. Terjemahan B. Sobran. Prinsip-prinsip Pemasaran. Jilid 1. Erlangga. Jakarta.

dan K. L. Keller. 2013. Marketing Management. $13^{\text {th }}$ Ed. Pearson Prentice Hall. New Jersey. Terjemahan B. Sobran. Manajemen Pemasaran. Jilid 2. Edisi 13. Erlangga. Jakarta.

Lotulung, S.C., J. Lapian., dan S. Moniharapan. 2015. Pengaruh Kualitas Produk, Harga dan WOM (Word of Mouth) terhadap Keputusan Pembelian Handphone Evercoss pada CV Trista Jaya Globalindo Manado. Jurnal Emba. 3 (3): 817-826.

Lupiyoadi, H. 2006. Manajemen Pemasaran Jasa. Edisi Kedua. Salemba Empat. Jakarta 
Mokoagouw, M.L. 2016. Pengaruh Gaya Hidup, Harga dan Kualitas Produk terhadap Keputusan Pembelian Handpone Samsung di Mobile IT Center Manado. E-Journal UNSRAT. 16 (1): 493-502.

Ratnaningrum, H. 2016. Pengaruh Promosi, Harga dan Kualitas Produk terhadap Keputusan Pembelian Konsumen dalam Pembelian BBM Jenis Pertalite di Kota Yogyakarta. Skripsi. Program Studi Pendidikan Ekonomi Universitas Sanata Dharma. Yogyakarta.

Schiffman, L. dan L.S. Kanuk. 2008. Perilaku Konsumen. Edisi Ketujuh. Indeks. Jakarta.

Tjiptono, F. 2008. Strategi Pemasaran. Edisi III. CV Andi Offset,Yogyakarta.

Yosevina, 2008. Word of Mouth. PMPM. 11(4): 5-13. 